Egyptian Journal of Aquatic Biology \& Fisheries

Zoology Department, Faculty of Science,

Ain Shams University, Cairo, Egypt.

ISSN $1110-6131$

Vol. 23(3): 245 - 255 (2019)

www.ejabf.journals.ekb.eg

\title{
The impact of shrimp pond effluent on water quality of Vasishta Godavari estuary with respect to brackishwater aquaculture, East Coast of India.
}

\author{
Ch Venkateswara rao ${ }^{*}$, NVHK Chari and R Muralikrishna. \\ Department of Physical,Nuclear Chemistry and Chemical Oceanography \\ School of Chemistry, Andhra University Visakhapatnam-530003, India. \\ *vrao.challagali@gmail.com.
}

\section{ARTICLE INFO \\ Article History: \\ Received: Feb. 21, 2019 \\ Accepted: June27, 2019 \\ Online:July 2019}

\section{Keywords:}

Vasishta Godavari

Estuary

Brackish water

aquaculture

shrimp pond

Stratification

\begin{abstract}
Estuary, where a river meets the Sea, provides high level nutrients both in water column and in sediment, making estuaries most productive natural habitat for brackish water aquaculture in the world. Estuary is subject both to marine influences and to river influences, causes variations in optimum hydro chemical parameters, which are suitable for brackish water aquaculture. Physicochemical studies were carried out to predict whether the variations are due to seasonal changes or due to aquaculture effluents in Vasishta Godavari Estuary (VGE).Towards this objective water samples were collected in VGE from five stations during Oct-2016; Monsoon with Farm Period (FP)-1 discharge, Jan-2017; Postmonsoon with FP-2 beginning ,June-17;Premonsoon with FP-3 discharge. Influence of seawater was felt in the estuary up to a distance of $40 \mathrm{~km}$ from the mouth towards the head.Though fluctuations in physicochemical parameters were noticed, these are in optimum range for brackish water aquaculture. Concentration of nitrate, silicate was rich, where as phosphate, nitrite was poor. Salinity stratification was more marked than that of dissolved oxygen. Salinity gradient (surface to bottom) increases towards seaward during the discharges of FP-1 \& FP-3 and not follows any trend during the beginning of FP-2. The field and laboratory observations on the water quality during the discharge and beginning of farm periods revealed that the study area have high potential for brackish water pond shrimp culture development based on values obtained which were in conformity with recommended values for shrimp culture.
\end{abstract}

\section{INTRODUCTION}

Estuary, where a river meets the sea provides high level nutrients both in water column and in sediment, making estuaries are most productive natural habitat for brackish water aquaculture (Simpson et al.(2001) and are considered to be excellent natural nursery grounds for a variety of fish and shrimp. (Kimirei et al. (2011); Minello et al.(2003); Dorenbosch et al.(2005.). The commercial exploitation of aquaculture activities is called "Blue Revolution" in the recent years. But the major problem in most of the estuaries is that the aquaculture pond effluents are drained into the estuarine waters, though they are used as source water for aquaculture. It shows the importance of research about the effect of shrimp farming on the environment with water pollution from shrimp pond effluents as the most common complaint. (Sara (2007); Boyd (2003); Anh et al. (2010); Bui et al. (2012.). 
Because of this problem aquaculture farmers experience difficulty in farming and changing their opinion from brackish water (inexpensive \& readily available) to ground water (expensive). Ground water has traditionally been less contaminated than surface water. Contamination of ground water sources is commonly observed in industrialized nations. Estuaries form a transition zone between river environments and maritime environments. They are subject both to marine influences such as tidal waves and influx of saline water and to river influences such as flow of fresh water and sediment (Sierra et al. (2002), causes variations in optimum hydro chemical parameters which are suitable for brackish water aquaculture. Therefore the main objective of this study is to bring awareness among the aquaculture farmers on suitability of these waters for resuming brackish water aquaculture, its promotion, and to examine the effluent loads from shrimp farms and its influence on this estuary.

The characterization of the shrimp farm's effluents in terms of water quality is very important to gauge the environmental health of an ecosystem in order to achieve a better regulation of the industry. (GESAMP (1996); Fuchs et al.(1999). To achieve this objective we selected the Vasishta Godavari Estuary (VGE), which is surrounded by brackish water aquaculture activities. Earlier studies reported in this estuary were mostly related to physicochemical and biological parameters (Sai Sastry et al. (1987); (1990); Padmavathi and Satyanarayana, 1999). However, did not focus on suitability of these water bodies for brackish water aquaculture. For this, seasonal variations in hydro chemical parameters were observed with respect to aquaculture farm periods might reveal whether changes are seasonal fluctuations or due to aquaculture discharges. If so, whether these changes are in desirable range or not for brackish water aquaculture

\section{MATERIALS AND METHODS}

The River Godavari is India's second longest river after the Ganga.At Dowaleswaram (16 56'59.99" N 8144'59.99" E) it bifurcates into two main distributaries called Vasishta Godavari and Gowthami Godavari. Vasishta Godavari is the western distributary of the Godavari,flows about $90 \mathrm{~km}$ from Dowaleswaram emptying into the Bay of Bengal at Antervedi $\left(16.3227^{\circ} \mathrm{N}, 81.7303^{\circ}\right.$ E)and Gowthami Godavari is the Eastern distributary,flows about $63 \mathrm{~km}$ from Dowaleswaram emptying into the Bay of Bengal at $\operatorname{Yanam}\left(16.7272^{\circ} \mathrm{N}, 82.2176^{\circ} \mathrm{E}\right)$. Both Vasishta Godavari Estuary (VGE) and Gowthami Godavari Estuary (GGE) together constitute the second biggest river-estuarine system along the east coast of India.

Based on seasonality of brackish water and based on water source, seasonal culture, tide dependent culture and pump dependent cultures are being practiced in this region (VGE). However, there are three usual Farm Periods (FP) in this region, they are FP-1. August-September-October; FP-2. January-February-March; FP-3. April-May-June; coinciding with annual flood phase, stable phase of moderate salinities, and drought phase of total marine domination respectively. Seasonal observations were done in correlation with farm periods in this estuary. i.e. October 2016, February 2017, and June 2017, which are represent the monsoon with FP-1 discharge, post monsoon-stable phase with FP-2 beginning and pre monsoon-drought phase with FP-3 discharge respectively. However there is small time bound (5-10 days) fluctuations among the farmers between FP-2 and FP-3. Field works were carried out in the estuary from mouth to head region and the effect of seawater penetration was felt upto $40 \mathrm{~km}$ upstream, usually these waters are called brackish 
waters. L. vannamei is the predominant species in brackish water aquaculture in the state. Beyond $40 \mathrm{~km}$ river bed remained practically dry during the non flood seasons and not suitable for aquaculture. Water samples were collected from five stations located in the lower (St.1 \& St.2), middle (St.3 \&4) and upper (St.5) reaches of Vasishta Godavari Estuary, i.e.,1,8,15,25,30 km from the confluence towards the head(Figure-1), where intense aquaculture activities are going on.

Water samples were collected from surface $(<1 \mathrm{~m})$ and bottom $(\sim 5$ or $10 \mathrm{~m}$, based on column depth) by using Niskin Sampler at the five stations, where aquaculture effluents(pond waters) are usually drained out. Dissolved Oxygen was fixed with Winkler's reagents onboard and determined by titrimetric method in the laboratory. Temperature was measured with a calibrated clean thermometer $\left( \pm 0.1^{\circ} \mathrm{C}\right)$ put in the Niskin sampler by opening its lid. Salinity was determined by argentometric titration method and the $\mathrm{pH}$ was measured on Thermo Scientific Orion Star bench top $\mathrm{pH}$ meter with accuracy of \pm 0.01 . All the samples were analyzed for remaining parameters viz., total ammonia nitrogen (TAN), nitrite nitrogen $\left(\mathrm{NO}_{2}-\mathrm{N}\right)$, nitrate nitrogen $\left(\mathrm{NO}_{3}-\mathrm{N}\right)$, phosphate, silicate, Biochemical Oxygen Demand (BOD), alkalinity, hydrogen sulphide $\left(\mathrm{H}_{2} \mathrm{~S}\right)$ by following the standard methods (Grassaph, et al. (1999); APHA (1989). Ammonia nitrogen $\left(\mathrm{NH}_{3}-\mathrm{N}\right)$ values were calculated from the values of TAN, salinity, temperature and $\mathrm{p}^{\mathrm{H}}$.

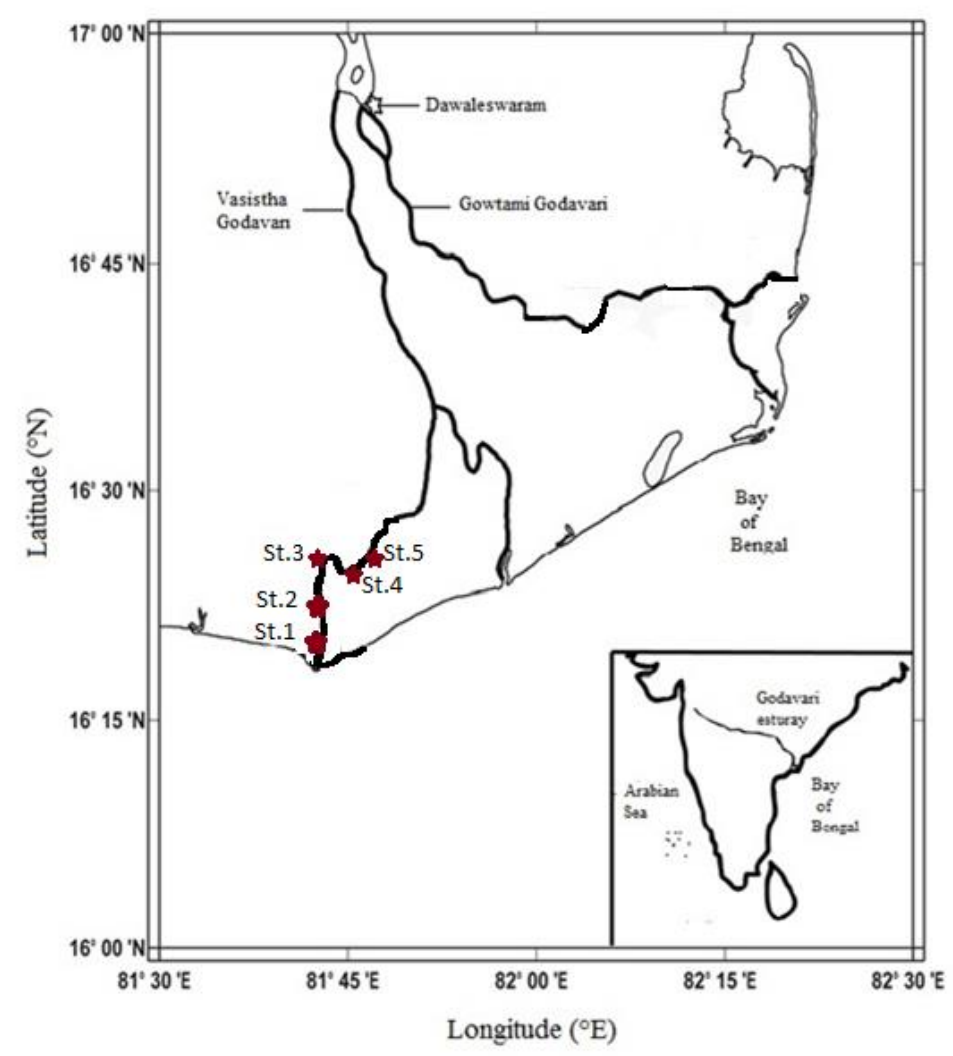

Fig. 1: Study Area-Stations Location Map.

\section{RESULTS AND DISCUSSION}

The Average \pm SD values of physico -chemical parameters at five sampling stations from the surface and bottom in three farm periods are presented in the Table 1. Hydrogen sulphide was not detected in any of the samples. All the water parameters were compared with the optimum levels suggested for brackish water 
aquaculture by Central Institute of Brackish Water Aquaculture and Ronald et al., (1999). Source Water Quality for Aquaculture, A Guide for Assessment.

Table 1: Analysis data of water quality parameters in three farm periods.

\begin{tabular}{|c|c|c|c|c|}
\hline $\begin{array}{l}\text { Water Quality } \\
\text { Parameter }\end{array}$ & $\begin{array}{l}\text { FP-1- Discharge } \\
\text { Average } \pm \text { SD } \\
\text { October-2016 }\end{array}$ & $\begin{array}{l}\text { FP-2-Beginning } \\
\text { Average } \pm \text { SD } \\
\text { Feb-2017 }\end{array}$ & $\begin{array}{l}\text { FP-3-Discharge } \\
\text { Average } \pm \text { SD } \\
\text { June-2017 }\end{array}$ & $\begin{array}{l}\text { Optimum } \\
\text { Value }\end{array}$ \\
\hline Temperature $\left({ }^{0} \mathrm{C}\right)$ & $28.95 \pm 0.15$ & $27.65 \pm 1.45$ & $32.2 \pm 1.27$ & $28-33$ \\
\hline$p^{\mathrm{H}}$ & $8.19 \pm 0.22$ & $7.92 \pm 0.22$ & $8.11 \pm 0.25$ & $7.5-8.5$ \\
\hline Salinity(ppt) & $9.98 \pm 8.57$ & $20.17 \pm 6.05$ & $19.99 \pm 10.85$ & $10-25$ \\
\hline $\mathrm{DO}^{1}(\mathrm{ppm})$ & $6.46 \pm 1.30$ & $7.86 \pm 0.65$ & $7.20 \pm 2.09$ & $5-6$ \\
\hline BOD $_{5}{ }^{2}-(\mathrm{ppm})$ & $1.41 \pm 0.77$ & $1.80 \pm 1.30$ & $1.33 \pm 1.66$ & $<10$ \\
\hline Alkalinity(ppm) & $151.12 \pm 34.62$ & $127.91 \pm 27.16$ & $136.14 \pm 22.55$ & $>80$ \\
\hline $\mathrm{H}_{2} \mathrm{~S}$ & $\mathrm{BDL}$ & $\mathrm{BDL}$ & BDL & \\
\hline $\mathrm{NO}_{2}{ }^{-} \mathrm{N}^{3}(\mathrm{ppm})$ & $0.029 \pm 0.004$ & $0.06 \pm 0.05$ & $0.12 \pm 0.14$ & $<0.25$ \\
\hline $\mathrm{NO}_{3}-\mathrm{N}^{4}(\mathrm{ppm})$ & $1.696 \pm 0.437$ & $0.495 \pm 0.181$ & $0.831 \pm 0.213$ & $0.10-0.2$ \\
\hline $\mathrm{PO}_{4}^{-3}-\mathrm{P}^{5}(\mathrm{ppm})$ & $0.585 \pm 0.212$ & $0.025 \pm 0.026$ & $0.041 \pm 0.009$ & $0.05-0.2$ \\
\hline $\mathrm{SiO}_{4}{ }^{-2}-\mathrm{Si}^{6}(\mathrm{ppm})$ & $9.167 \pm 3.757$ & $0.369 \pm 0.262$ & $12.488 \pm 2.769$ & ---- \\
\hline Total Ammonia & $0.127 \pm 0.00053$ & $0.128 \pm 0.00025$ & $0.127 \pm 0.00059$ & $<1$ \\
\hline Nitrogen (TAN) & & & & $0.1-1.0$ \\
\hline$\left(\mathrm{NH}_{4}+\mathrm{NH}_{3}\right)(\mathbf{p p m})$ & & & & Clifford1994 \\
\hline Unionized & $0.014 \pm 0.00769$ & $0.0068 \pm 0.00438$ & $0.015 \pm 0.01003$ & $<0.1$ \\
\hline $\begin{array}{l}\text { Ammonia }\left(\mathrm{NH}_{3}-\right. \\
\mathrm{N})(\mathrm{ppm})\end{array}$ & & & & Clifford 1994 \\
\hline
\end{tabular}

1. Dissolved Oxygen 2. 5-day Biochemical Oxygen Demand. 3. Nitrite 4.Nitrate 5. Phosphate. 6. Silicate. SD: Standard Deviation.; ppm:parts per million (or) mg/L; ppt: parts per trillion.

\section{Temperature:}

The Temperature of water was obtained $28.95 \pm 0.15^{\circ} \mathrm{C}, 32.2 \pm 1.27{ }^{\circ} \mathrm{C}$ during the discharge of FP-1 and FP-3 respectively, coinciding with annual flood phase(river discharge),drought phase(summer), and $27.65 \pm 1.45$ during the FP-2 beginning coinciding with stable phase(winter). which was also reported in this estuary (Padmavathi and Satyanarayana, 1999; SaiSastry and Chadramohan, 1990.). The temperatures observed during farm periods discharge and farm period beginnings were still suitable for brackish water aquaculture.

pH :

The $\mathrm{p}^{\mathrm{H}}$ of natural waters is greatly influenced by the concentration of carbon dioxide which is an acidic gas (Boyd, 1979). The $\mathrm{p}^{\mathrm{H}}$ values were obtained 8.19 \pm 0.22 , $8.11 \pm 0.25$ during the discharge of FP-1 and FP-3 respectively, coinciding with annual flood phase, stable phase and 7.92 \pm 0.22 during the FP-2 beginning coinciding with stable phase. Relatively high $\mathrm{p}^{\mathrm{H}}$ values are obtained for FP-1 and FP-3 when compared with FP-2 beginning is due to removal of $\mathrm{CO}_{2}$ during the process of photosynthesis. (Rajasegar, (2003). However, observed $\mathrm{p}^{\mathrm{H}}$ values during farm periods discharge and farm period beginning were still suitable for brackish water aquaculture.

Salinity:

Salinity is a major driving factor that affects the density and growth of aquatic organisms population. The Salinity values were obtained $9.98 \pm 8.57 \mathrm{ppt}, 19.99 \pm 10.85$ ppt during the discharge of farm periods FP-1 and FP-3 respectively coinciding with annual flood phase, drought phase and 20.17 \pm 6.05 during the beginning of FP-2 coinciding with stable phase. Relatively high salinity values in FP-3 discharge corresponding to drought phase due to total marine domination (SaiSastry and Chadramohan, 1990), moderate salinities corresponding to stable phase (FP-2 beginning) due to adequate mixing of water column (SaiSastry and Chadramohan, 
1990). A very low salinity values correspond to annual flood phase is due to river discharge. However, observed salinity values during discharge of FP-1, FP-3 and beginning of FP-2 were still suitable for brackish water aquaculture.

\section{Dissolved Oxygen:}

Dissolved Oxygen (DO) is a very basic requirement for aquaculture species. Maintenance of an adequate level of DO is very important for shrimp/fish survival and prolonged exposure to the stress of low concentration of oxygen can inhibit shrimp growth. DO is a very complex parameter because its concentration is dependent on many processes. DO concentrations were obtained $6.46 \pm 1.30 \mathrm{ppm}$, $7.20 \pm 2.09 \mathrm{ppm}$ during the discharge of FP-1 and FP-3 respectively coinciding with annual flood phase, drought phase and $7.86 \pm 0.65 \mathrm{ppm}$ corresponds to the beginning of FP-2 coinciding with stable phase. The DO values during the three farm periods exceeds the optimum values suggested by CIBA, Ronald et al. (1999), Boyd (1990).

Relatively higher concentration of DO during the discharge of FP-3 compared to other farm periods was due to discharge of the river. High concentrations of DO during the FP-1 and FP-2 compared with optimum values may be due to, oxygen enters water through photosynthesis by aquatic plants, principally phytoplankton (Watt (2000) and by diffusion at the air-water interface. Waves and wind help put oxygen into the water.

\section{BOD:}

The Biochemical Oxygen Demand (BOD) is a measure of the amount of organic compounds that can be biologically oxidized by naturally occurring microorganisms in water and is often used as a surrogate of the degree of organic pollution of water (Sawyer et al. (2003), it is important in aquaculture because the degradation of organic matter by microorganisms is a major sink for dissolved oxygen, a parameter of fundamental importance to aquaculture. The Biochemical Oxygen Demand $\left(\mathrm{BOD}_{5}\right)$ values obtained were $1.41 \pm 0.77 \mathrm{ppm}, 1.33 \pm 1.66 \mathrm{ppm}$ during the discharge of FP-1 and FP-3 respectively coinciding with annual flood phase, drought phase and $1.80 \pm 1.30 \mathrm{ppm}$ during the beginning of farm period FP-2 coinciding with stable phase. These obtained $\mathrm{BOD}_{5}$ values were still suitable for brackish water aquaculture.

\section{Nutrients:}

The Concentrations of nutrients present in three farm periods are shown in the Fig. 2 (a), 2(b), 2(c).

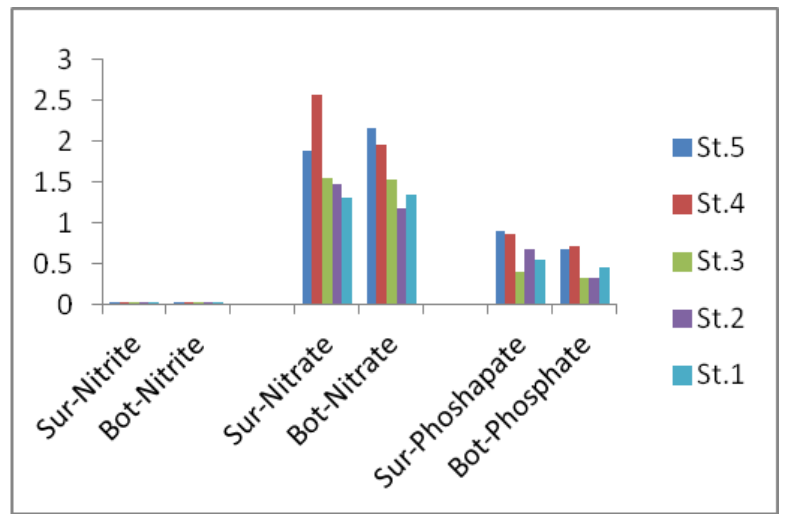

Fig. 2 (a): Oct-16; FP-1Discharge 


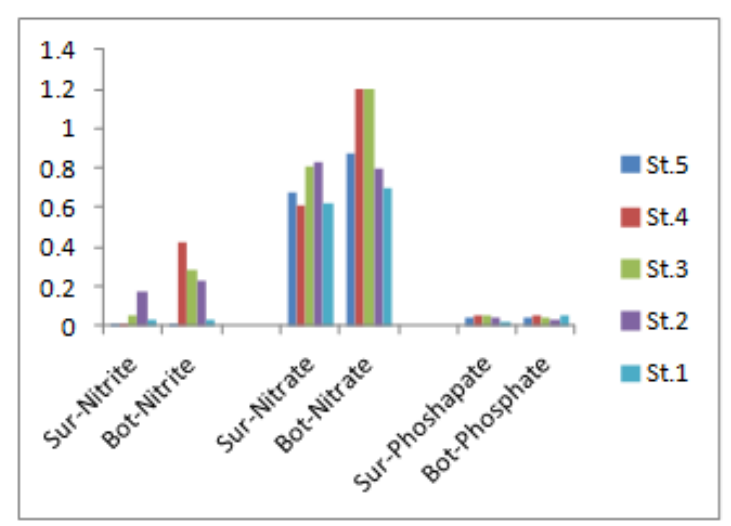

Fig. 2 (b): Jan-17; FP-2 Beginning.

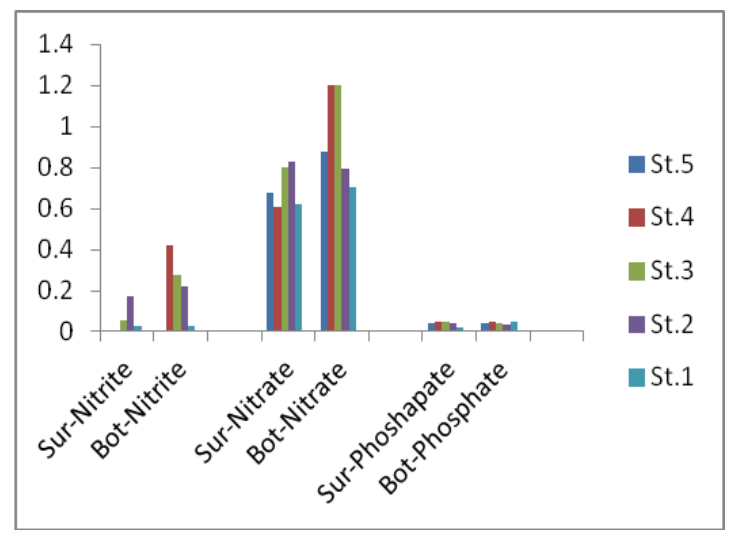

Fig. 2(c): Jun-17; FP-3 Discharge.

Nitrate is the least toxic of the major inorganic nitrogen compounds. It is formed as the end product of nitrification process and concentrations are generally higher than both ammonia and nitrite. High levels of nitrate can affect the osmoregualtion and oxygen transport. (Lawson (1995).High nitrate concentration levels can also result in eutrophication and excessive growth of algae and aquatic plants which might have negative impact on culture species. The nitrate values obtained were $1.696 \pm 0.437 \mathrm{ppm}, 0.831 \pm 0.213 \mathrm{ppm}$ during the discharge of farm periods FP-1 and FP-3 respectively coinciding with annual flood phase, drought phase and $0.495 \pm 0.181 \mathrm{ppm}$ during the beginning of FP-2 coinciding with stable phase. These obtained values of nitrate were exceeds the optimum values.

Nitrite is formed primarily as an intermediary in the conversion of ammonia to nitrate, a process known as nitrification, it gets converted to nitrate end product quickly, due to this ,high nitrite concentration are not common in aquatic systems. In fact nitrite is not a common source water problem, but it becomes problem during the operation of recirculating systems where the water is continually reused. (Lawson (1995). The nitrite values obtained were $0.029 \pm 0.004 \mathrm{ppm}, 0.12 \pm 0.14 \mathrm{ppm}$ during the discharge of FP-1 and FP-3 respectively coinciding with annual flood phase, drought phase and $0.06 \pm 0.05 \mathrm{ppm}$ during the beginning of FP-2 coinciding with stable phase. These obtained values of nitrite were low compared with optimum values. This was also reported in this estuary. (Sai Sastry (1987).

The Concentrations of Phosphate values obtained were $0.585 \pm 0.212 \mathrm{ppm}$, $0.041 \pm 0.009 \mathrm{ppm}$ during the discharge of FP-1 and FP-3 respectively coinciding with annual flood phase, drought phase and $0.025 \pm 0.026 \mathrm{ppm}$ during beginning of FP-2 coinciding with stable phase. These obtained values of phosphate were low 
compared with optimum values except during FP-1 discharge. Considerable depletion of nitrite and phosphate during discharge and beginning of farm periods coinciding with blooms of phytoplankton. This was also reported in this estuary (Sai Sastry (1987).

Vasishta Godavari estuary was poor in Phosphate, Nitrite and rich in Nitrate and Silicate. This was also reported in this estuary (Sai Sastry and Chandramohan, 1990) and attributed to the lack of extensive mud banks and mangrove swamps adjoining it(Seshappa. (1953).

\section{Alkalinity:}

The source of alkalinity in water is due to salts of weak acids becoming dissociated in water. Most of alkalinity composed of carbon ions $\left(\mathrm{CO}_{3}{ }^{2-}\right.$ and $\left.\mathrm{HCO}_{3}{ }^{-}\right)$ their proportions depends on $\mathrm{p}^{\mathrm{H}}$. At $\mathrm{p}^{\mathrm{H}}$ about 4 , most of the alkalinity is in the form of $\mathrm{CO}_{2}$, as the $\mathrm{p}^{\mathrm{H}}$ increased Bicarbonate becomes more common until 8.3, as $\mathrm{pH}$ continues to raise Carbonate becomes more common. Meade (1989.). Since pH ranged from 7.92 to 8.19 in VGE waters; alkalinity, in fact most of the inorganic carbon is in the form of bicarbonate. Alkalinity values obtained were 151.12 \pm 34.62 ppm, 136.14 $\pm 22.55 \mathrm{ppm}$ during the discharge of FP-1 and FP-3 respectively coinciding with annual flood phase, drought phase and $127.91 \pm 27.16 \mathrm{ppm}$ during the beginning of FP-2 coinciding with stable phase. These obtained values still in the desirable range for aquaculture as suggested by Meade (1989) and Tucker and Robinson, 1990.

\section{TAN:}

Total Ammonia Nitrogen (TAN) values obtained were $0.127 \pm 0.00053 \mathrm{ppm}$, $0.127 \pm 0.00059 \mathrm{ppm}$ during the discharge of FP-1 and FP-3 respectively coinciding with annual flood phase, drought phase and $0.128 \pm 0.00025 \mathrm{ppm}$ during the beginning of FP-2 coinciding with stable phase. These obtained values are still in the desirable range for aquaculture as suggested by CIBA, Clifford (1994).

\section{Ammonia:}

Ammonia content $\left(\mathrm{NH}_{3}-\mathrm{N}\right)$ obtained was $0.014 \pm 0.00769 \mathrm{ppm}, 0.015 \pm 0.01003$ ppm during the discharge of FP-1 and FP-3 respectively coinciding with annual flood phase, drought phase and $0.0068 \pm 0.00438 \mathrm{ppm}$ during the beginning of farm period FP-2 coinciding with stable phase. These Ammonia contents found were still in the save limit for aquaculture suggested by Clifford(1994). The levels of ammonia were found relatively higher, during the discharge FP-1 and FP-3 than beginning of FP-3 possibly due discharge of organic rich effluents and liberation of ammonia by decomposition process( Priyadarshini and Abraham, 2016).

Salinity stratification and DO stratification was observed during the study. Thermal stratification was not observed during the study.

Significant horizontal salinity gradient (surface to bottom) was observed towards the head shows that the Vasishta Godavari is normal like any other Indian estuaries (RamaSarma (1965); Cherian, et al. (1975) and is increases from head(St.1) to mouth (St.5) in all the farm periods irrespective of farm discharge and farm beginning, corresponding to this salinity trend from head to mouth, dissolved oxygen gradient from surface to bottom decreases from head to mouth as the salt water holds less oxygen. (Table 2 \& Figures 3(a), 3(b), 3(c)) 
Table 2: Salinity (ppt), DO (ppm) values for five stations at Surface and Bottom

\begin{tabular}{|c|c|c|c|c|c|c|c|}
\hline \multirow[t]{2}{*}{ Station } & 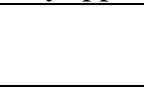 & \multicolumn{2}{|c|}{$\begin{array}{l}\text { Farm Period-1 } \\
\text { Discharge }\end{array}$} & \multicolumn{2}{|c|}{$\begin{array}{l}\text { Farm Period-2 } \\
\text { Beginning }\end{array}$} & \multicolumn{2}{|c|}{$\begin{array}{l}\text { Farm Period-3 } \\
\text { Discharge }\end{array}$} \\
\hline & & Surface & Bottom & Surface & Bottom & Surface & Bottom \\
\hline \multirow{2}{*}{ Station 5} & Salinity & 0.304 & 0.456 & 12.192 & 13.237 & 4.118 & 4.680 \\
\hline & DO & 8.401 & 8.474 & 8.481 & 8.001 & 11.841 & 8.481 \\
\hline \multirow[t]{2}{*}{ Station 4} & Salinity & 0.608 & 4.414 & 14.631 & 21.076 & 10.297 & 20.969 \\
\hline & DO & 7.817 & 5.479 & 8.561 & 7.601 & 8.481 & 4.480 \\
\hline \multirow[t]{2}{*}{ Station 3} & Salinity & 9.437 & 17.657 & 15.502 & 15.502 & 16.475 & 28.083 \\
\hline & DO & 6.210 & 5.114 & 8.001 & 6.401 & 7.121 & 5.280 \\
\hline \multirow[t]{2}{*}{ Station 2} & Salinity & 10.655 & 21.158 & 20.205 & 20.205 & 21.343 & 29.955 \\
\hline & DO & 6.502 & 5.114 & 8.401 & 8.401 & 5.920 & 5.920 \\
\hline \multirow[t]{2}{*}{ Station 1} & Salinity & 12.177 & 22.985 & 22.643 & 26.824 & 29.581 & 34.449 \\
\hline & DO & 5.990 & 5.552 & 8.241 & 7.681 & 7.041 & 7.521 \\
\hline
\end{tabular}
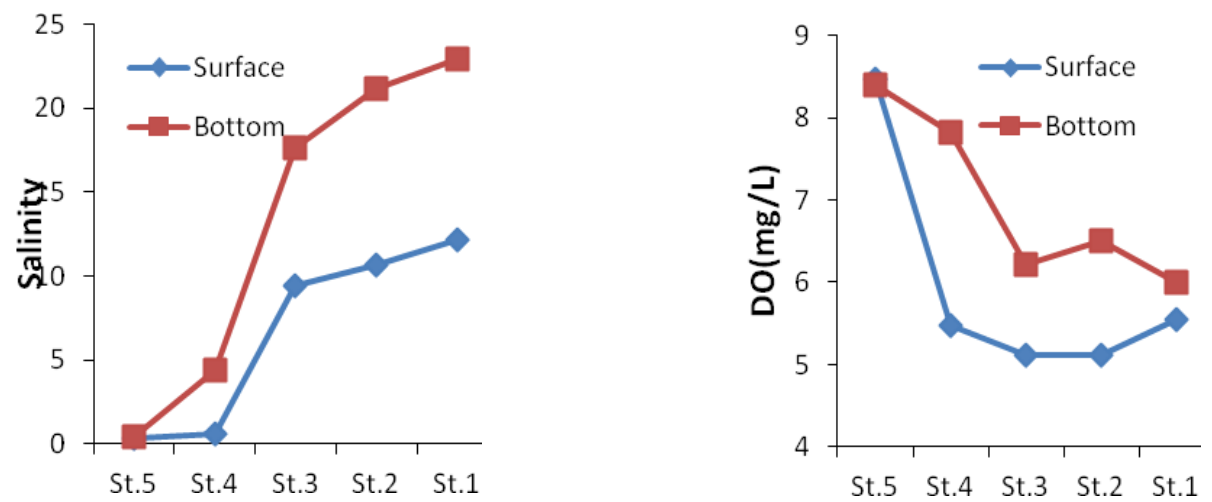

Fig. 3 (a): Oct-16;FP-1 Discharge
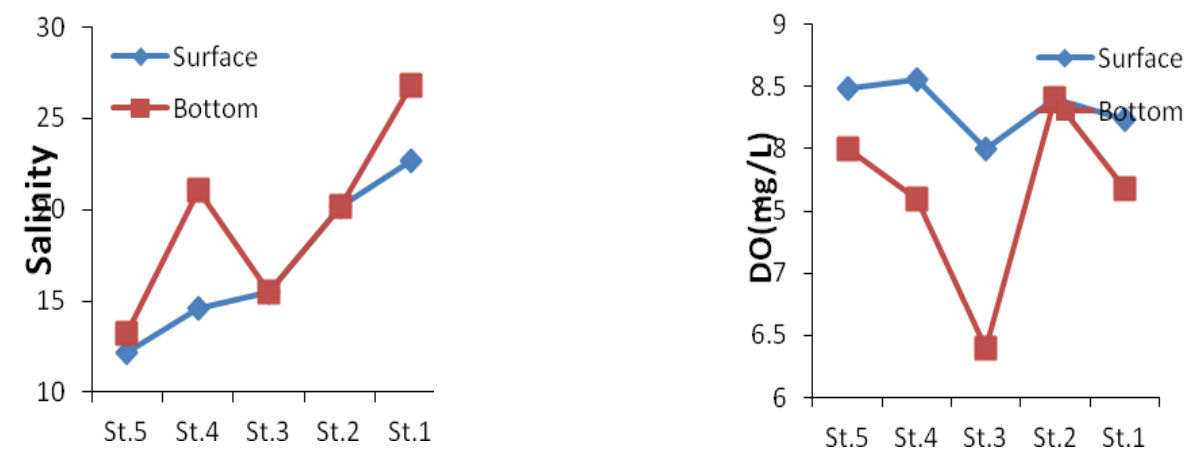

Fig. 3 (b): Jan-17; FP-2 Begining.
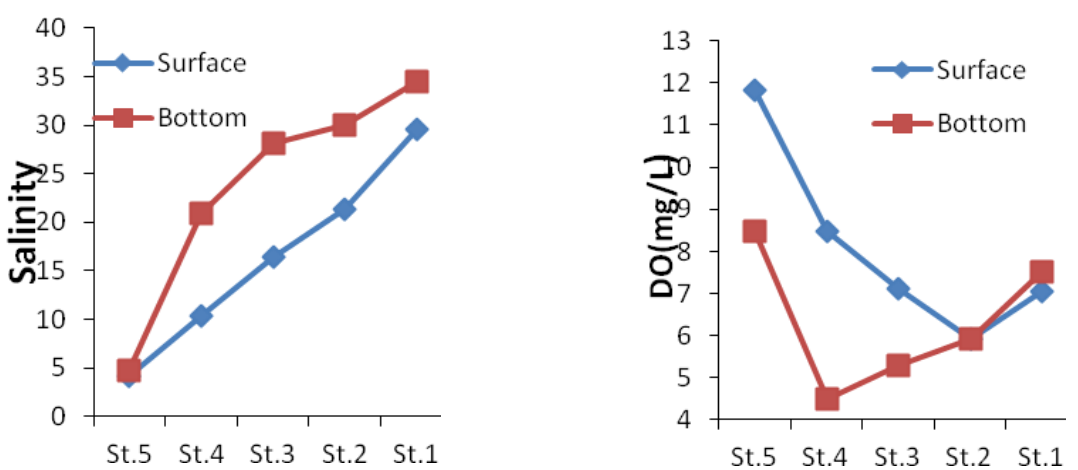

Fig. 3(c): Jun-17; FP-3 Discharge 
DO stratification was comparatively higher during the discharge of FP-1 and FP-3 than beginning of FP-2 and particularly at Station-2 \& Station-3 was observed. This was primarily due to greater depth of the water column, frequent addition of farm drainage and decomposition of phytoplankton in abundance. This was also reported earlier in this estuary. (Sai Sastry and Chandramohan, 1990).

Significant vertical salinity stratification was observed during the discharge of FP-1, FP-3 at stations 2,3,4,5 and beginning of FP-2 may be due to recovery, drought and stable phases of river respectively, this was also reported earlier in this estuary (Sai Sastry and Chandramohan, 1990).Salinity stratification is less at St.1 in FP-3 discharge during drought phase suggest that cellular type of circulation in operation as has been reported from other estuaries.(Ramasarma and Ganapathi, 1968; Ramamoorthi and Venugopalan, 1976)

Surface to bottom differences are insignificant at St.3 and St.4 in FP-2 beginning of stable phase was observed. This was because of the proximity of the former to the turbulent confluence and shallowness coupled with adequate mixing of water column. This was reported earlier in this estuary. (Sai Sastry and Chandramohan, 1990).

\section{CONCLUSION}

The Present study summarizes the seasonal fluctuations of various physico chemical parameters for brackish water aquaculture with respect to aquaculture farm periods in the Vasishta Godavari estuary as exploratory statistical data output, has provided information about the water quality status of Vasishta Godavari Estuary and its suitability for aquaculture uses. The field and laboratory observations on the water quality during the discharge and beginning of farm periods revealed that the study area have high potential for brackish water pond shrimp culture development based on values obtained which were in conformity with recommended values for shrimp culture. This preliminary study reveals that all the fluctuations in physicochemical parameters during discharge and beginning of farm periods are strictly due to seasonal changes not due to the aquaculture effluents. The source water which receives aquaculture effluents has sufficient flushing capacity due to the freshwater inflow; possible influx of nutrient rich water into estuary along with tide of semidiurnal type with two highs and two lows in a day makes the estuarine waters suitable for brackish water aquaculture up to the study area. This envisages that the aquaculture effluents impact on this estuarine waters (source water) is transient not perennial. It is suggested that a more precise further studies are required in this region by collecting the water samples (daily, weekly, fortnightly and/or during tidal cycles) at inlet, pond, and outlet for these stations to estimate the transient effect of aquaculture effluents on this estuary.

\section{ACKNOWLEDGEMENTS}

The authors are thankful to the farmers of Vasishta Godavari estuary region for their cooperation during the study period. All farm owners are sincerely acknowledged for their co-operation. The authors acknowledge to Prof. Nittala S. Sarma (Emeritus Scientist, CSIR) for providing instrumental facilities.

FUNDING SOURCES: The research is not funded by any Institution / Organisation. 


\section{REFERENCES}

APHA (1989). Standard methods for the examination of water and wastewater, Part 3, $17^{\text {th }}$ American Public Health Association, Washington DC, 164.

Anh, Pham Thi.; Carolein Kroeze.; Simon R. Bush. and Arthur, P. J. Mol. (2010). Water pollution by intensive brackish shrimp farming in south-east Vietnam: causes and options for control. Agri. Water. Manag., 97(6): 872-882.

Boyd, C. E. (1979). Water quality in warm water fish ponds. Craftmaster Auburn, Alabama, USA, Printers Inc.-359 pages.

Boyd, C. E. (1990). Water quality in ponds for aquaculture. Agriculture Experiment Station, Auburn University, Alabama.Science-482 pages

Boyd C. E. (2003). "Guidelines for aquaculture effluent management at the farmlevel," Aquaculture., 226(1-4): 101-112.

Bui Thuyet D.; Jim Luong-Van. and Chris M. Austin (2012). Impact of shrimp farm effluent on water quality in coastal areas of the world heritage-listed Ha Long Bay.American J. Envi. Sci., 8 (2):104-116.

Cherian,T.; Rao, L V G. and Varma, K K. (1975). Studies on Nutrients of Mandovi and Zuari river systems. Indian J Mar Sci., 4(5)

Clifford, Henry C. (1994). Semi-Intensive Sensation: A Case Study in Marine Shrimp Pond Management. World Aquaculture. Baton Rouge.6-6

Dorenbosch, M; Grol, M. G. G.; Christianen, M.J.A.; Nagelkerken, I. and Velde, Van der G. (2005). Indo-Pacific seagrass beds and mangroves contribute to fish density and diversity on adjacent reefs. Mar. Eco. Prog. Series., 302: 63-76.

Fuchs, J.; Martin, J. L. M. and An, N. T. (1999). An Impact of tropical shrimp aquaculture on the environment in Asia and the Pacific. Euro. Comm. Fish. Coop. Bull., 12(4): 9-13.

GESAMP (1996). The ecological effects of coastal aquaculturewastes," Report Studies GESAMP 57,IMO/FAO/UNESCOIOC/WMO/WHO/IAEA/UN/UNEP Joint Group of Experts on the Scientific Aspects of Marine Environmental Protection, Rome, Italy, 1996.

Grasshoff, K.; Ehrhardt, M.; and Kremling, K. (1999). (Eds.), Methods of Seawater Analysis, third ed. Verlag Chemie, Weinheim (pub), pp. 603

Kimirei, Ismael.; Nagelkerken, Ivan.; Griffioen, Ben. and Wagner, Coen. (2011). Ontogenetic habitat use by mangrove/seagrass-associated coral reef fishes shows flexibility in time and space. Estu., Coa. and Shelf Sci., 92: 47-58.

Lawson, Thomas B. ( 1995). Fundamentals of Aquacultural Engineering. New York: Chapman and Hall.

Meade, J. W. (1989). Aquaculture Management. Publisher: Springer US; Copyright Holder: Van Nostrand Reinhold.

Minello, T. J.; Able, K. W.; Weinstein, P Michael. and Hays, Cynthia (2003). Salt marshes as nurseries for nekton: testing hypotheses on density, growth and survival through meta-analysis. Mar. Eco. Prog. Series., 246: 39-59.

Padmavathi, D. and Satyanarayana, D. (1999). Distribution of nutrients and major elements in riverine, estuarine and adjoining coastal waters of Godavari, Bay of Bengal. Ind. J. Mar. Sci., 28: 345-354

Priyadarsani, Leesa. and Abraham, Thangapalam. Jawahar.(2016). Water and sediment quality characteristics of medium saline traditional shrimp culture system (bheri). J. Fish., 4(1): 309-318.

Rams Sarma D V (1965), Hydrography of the Godavari estuary, Ph. D. thesis, Andhra University. 
Ramasarma, D.V. and Ganapati, P.N. (1968). Hydrography of the Kakinada Bay. Proc. Sym. Ind. Ocean. Bull. Nat. Inst. Sci. Ind., 38 (I): 49-79.

Ramamoorthi,K and Venugopalan, V K.(1976).Distribution of salinity and mixing patterns in the Vellar estuary. J. Mar. Biol. Ass. Ind., 18:461-468

Ronald, D.Zweig.; Morton, John D. and Stewart, Macol M.(1999). Source Water Quality for Aquaculture, A Guide for Assessment. World Bank publisher.

Rajasegar, M. (2003). Physico-chemical characteristics of the Vellar estuary in relation to shrimp farming. J. Environ. Biol., 24: 95-101.

Seshappa, G. (1953). Phosphate Content of Mud banks along the Malabar Coast. Nature., 171(4351): 526-527

Sai Sastry A.G.R. (1987). Studies on the hydrography and plankton of a tropical tidal estuary (The Vasishta Godavari) on the east coast of India. Ph.D. Thesis.

SaiSastry, A.G.R. and Chandramohan, P. (1990a).Physicochemical characteristics of Vasishta- Godavari Estuary, eastcoast of India: Pre-pollution status. Ind. J. Mar. Sci., 19: 42-46.

Simpson, J. H.; Vennell, R. and Souza, A J. (2001). The salt fluxes in a tidallyenergetic estuary. Estu. Coa. and Shelf Sci., 52(1): 131-142

Sierra, Joan Pau.; Sanchez-Arcilla, A.; Gonzalez del Rio, J. and Flos, Jordi. (2002). Spatial distribution of nutrients in the Ebro estuary and plume. Conti. Shelf Res., 22(2): 361-378.

Sawyer, Clair N.; McCarty, Perry L. and Parkin, Gene F. (2003). Chemistry for Environmental Engineering and Science ( $5^{\text {th }}$ ed.). New York: McGraw-Hill. ISBN 0-07-248066-1.

Sar`a G. (2007). Ecological effects of aquaculture on living and nonliving suspended fractions of the water column: a meta analysis. Water Research. 41(15) : 31873200 .

Tucker, Craig S. and E. H. Robinson (1990). Channel Catfish Farming Handbook. New York: Van Nos- trand Reinhold.

Watt, M. K. (2000). A Hydrologic Primer for New Jersey Watershed Management (Water-Resources Investigation Report 00-4140). West Trenton, NJ: U.S. Geological Survey.) 